Flávia Biroli

Universidade de Brasília

\title{
Autonomia, opressão e identidades: a ressignificação da experiência na teoria política feminista
}

\begin{abstract}
Resumo: O artigo analisa abordagens distintas para a relação entre autonomia, opressão e construção das identidades na teoria política feminista. Tomando como ponto de partida os conceitos de "corpo vivido" e "conhecimento vivido", discute as possibilidades de ressignificação da experiência e definição autônoma das identidades em contextos sociais em que prevalecem relações de poder desiguais e assimétricas. Um dos problemas enfocados é o fato de que as identidades, ainda que caras aos indivíduos, possam reproduzir os valores que estão na base da sua condição de subalternidade e que justificam as formas presentes de opressão. Por outro lado, considera em que medida, e de que formas, os indivíduos responderiam ativamente às alternativas restritas que as estruturas de poder oferecem, podendo reconfigurálas e, no limite, confrontá-las. Procura, assim, considerar aspectos e matizes nessas abordagens que permitem superar a oposição entre escolhas autônomas e coerção.
\end{abstract}

Palavras-chave: gênero; teoria política feminista; autonomia; opressão; identidade; experiência.

Copyright $\odot 2013$ by Revista Estudos Feministas.

\footnotetext{
1 As discussões presentes neste artigo integram as pesquisas "Desafios da teoria democrática numa ordem desigual: contribuições das teorias políticas feministas" (edital MCT/CNPq/SPM-PR/MDA $\left.n^{\circ} 20 / 2010\right)$ e "Desigualdade e preferências: a tensão entre o valor da autonomia individual e a crítica à opressão na teoria política contemporânea" (PQ/CNPq). Agradeço a Luis Felipe Miguel pela leitura. ${ }^{2}$ Anne PHILLIPS, 2007, p. 150.

${ }^{3}$ Cass R. SUNSTEIN, 2009[1991], p. 5.
}

O processo de produção das opiniões, das preferências e dos interesses não é individual, mas remete às posições em uma coletividade, em redes desiguais que se estabelecem em contextos sociais concretos. ${ }^{1}$ Essa compreensão vincula as opções dos indivíduos aos padrões de socialização e às variantes institucionais. São estes que definem o horizonte em relação ao qual se organizam identidades que estão, por sua vez, na base do entendimento que se tem dos próprios projetos e ambições, assim como daquilo que define o bem-estar para cada indivíduo. Pode-se, nesse sentido, considerar que as preferências são "aprendidas"2 ou "adaptativas", constituídas por fatores que incluem "o contexto em que a preferência é expressa, as regras legais existentes, escolhas passadas de consumo e a cultura em geral". ${ }^{3}$ 
Seria possível desdobrar esse entendimento em uma compreensão de que, sendo as preferências aprendidas, as escolhas - e a própria identidade dos indivíduos - são uma consequência de padrões e valores sociais que os definem, de certo modo, a partir de "fora". Em certo sentido, isso significaria negar que existam de fato escolhas. Mas pode-se entender, diferentemente, que o que essa posição nega, no limite, é o entendimento de que as preferências são sempre aprendidas porque as considera à luz de outra noção, a de preferências "próprias". Em outras palavras, e sem avançar de maneira precisa nessa discussão neste momento, estaríamos trabalhando com uma oposição entre agência individual e estruturas (valores, constrangimentos, instituições) sociais.

O problema se torna mais complexo e mais nuançado, no entanto, quando entendemos que as identidades dos indivíduos são socialmente aprendidas, mas que esse não é um ponto de chegada para as reflexões sobre o impacto das estruturas e as formas que a ação individual assume. Considerar suas escolhas - e o grau de autonomia nelas envolvido - é considerá-las a partir dessa base, isto é, de sua inserção no contexto de relações sociais concretas. O fato de que são socialmente constituídas e motivadas não significa, no entanto, que os indivíduos não façam escolhas e que estas não tenham impacto na definição das suas vidas. Mas significa que são feitas em meio a pressões, interpelações e constrangimentos que não são necessariamente percebidos como tal.

Assim, o problema da constituição autônoma das identidades, que é objeto deste artigo, não se define na oposição entre autonomia individual e produção social da individualidade. Partir dessa premissa, que é de fato a orientação mais fundamental assumida neste artigo, não esgota o problema. Daí a necessidade de analisar diferentes abordagens para esse problema num campo da teoria política em que a crítica à opressão e a análise da constituição diferenciada das identidades (em alguns casos, como reação à opressão, em outros como sua reprodução) vem sendo fecundo, a teoria política feminista.

Uma das questões que se colocam, e que é particularmente relevante para esta discussão, é se é possível levar em conta as influências e limites na definição das preferências dos indivíduos sem jogar fora a noção de que são (segundo uma definição e em um grau que precisam ser definidos) autônomos. Em outras palavras, se é possível sustentar que as opções dos indivíduos devem ser consideradas, valorizando sua experiência ${ }^{4}$ e tomando como

${ }^{4}$ Iris YOUNG, 2005

5 Jean COHEN, 1997, p. 149. relevante a noção de "autonomia decisional", ${ }^{5}$ sem desconsiderar que suas percepções se definem em redes 
${ }^{\circ}$ Nancy FRASER, 1997.

\begin{abstract}
7 Jean Bethke ELSHTAIN, 1981 : Carol GILLIGAN, 1982; Sarah RUDDICK, 1989.
\end{abstract}

${ }^{8}$ Elizabeth BADINTER, 1985[1980].

9 Luis Felipe MIGUEL, 2001; Luis
Felipe MIGUEL e Flávia BIROLI,
2011 ; Susan OKIN, 1998; PHILLIPS,
1991 .
${ }^{10}$ Flávia BIROLI, 2011 ; Ellen SEITER,
1986.

${ }^{11}$ Toril MOI, 1999, p. 104. intrincadas de incitações e constrangimentos sociais que envolvem relações de poder.

As percepções individuais podem resultar de formas de opressão que mobilizam e naturalizam valores que, mesmo sendo desvantajosos e colocando os indivíduos em posições de subordinação, estão na base de suas identidades - e, portanto, de como percebem seus interesses e elaboram suas preferências. Por outro lado, o destaque à opressão como forma de apagamento da autonomia poderia desdobrar-se em uma desvalorização (política e cognitiva) das opções feitas pelos indivíduos, assim como de sua vivência concreta e específica. Também as ressignificações das normas e convenções sociais ao longo do tempo, com seu impacto sobre a vivência dos indivíduos e a construção das identidades, poderiam ser desconsideradas ou perder peso nas análises. ${ }^{6}$

Na teoria política feminista, esse debate é composto por abordagens variadas, e distintas nos seus pressupostos, e pode ser exemplificado pela análise da relação entre mulher, maternidade e família. Em algumas abordagens, a relação entre as mulheres e o cuidado com os filhos ou indivíduos vulnerabilizados (como os idosos) é entendida como a base para valores diferenciados e para uma ética distinta. A relação entre as mulheres e a vida doméstica, tal como produzida pela divisão convencional dos papéis sexuais, não se constituiria, assim, como um obstáculo à definição autônoma de seus interesses, de sua "voz" e de sua participação política. ${ }^{7}$ Em outras abordagens, diferentemente, é ressaltada não apenas a historicidade desses valores e das identidades neles fundadas, ${ }^{8}$ mas também o fato de que contribuíram e contribuem para naturalizar formas de opressão que estão na base dos obstáculos à atuação das mulheres nas esferas profissional e política. ${ }^{9}$ Um dos aspectos dessa crítica ressalta a relação entre os estereótipos e a internalização da opressão. ${ }^{10}$ Ainda que estejam na base de compreensões socialmente legitimadas do que diferencia mulheres e homens, a própria definição de determinados atributos e comportamentos como femininos ocultaria o fato de que "não têm quaisquer conexões intrínsecas ou necessárias, mas apenas ideológicas, com as mulheres ou o corpo feminino". ${ }^{11}$

O ponto de partida para a discussão neste artigo são os conceitos de "corpo vivido", tal como mobilizado por Iris Marion Young em On Female's Body Experience, e de "conhecimento vivido", do modo como é definido na análise de Catharine A. Mackinnon em Towards a feminist theory of the State. A partir desses conceitos, mas também de argumentos e posições sustentados mais amplamente nas obras de Mackinnon e Young, procuramos situar duas 
abordagens diferenciadas para os problemas relacionados à produção autônoma das identidades. As possibilidades de ressignificação da experiência e definição autônoma das identidades em contextos sociais em que prevalecem relações de poder desiguais e assimétricas são consideradas de maneiras diversas pelas autoras, permitindo avançar nessa discussão.

Na primeira seção do artigo, discutimos a valorização das experiências específicas das mulheres, e das identidades a elas relacionadas. O foco central é a análise das possibilidades de ressignificação da experiência, sem desconsiderar as relações de opressão nas quais tomam parte em posição de desvantagem. A segunda seção discute abordagens que enfatizam, diferentemente, as restrições à vivência e à construção de identidades alternativas, e autônomas, quando há opressão sistemática a um grupo social, no caso às mulheres. Nela, o foco vai para as tensões entre identidades autonomamente constituídas e preferências aprendidas, que potencialmente reproduziriam os padrões de opressão vigentes. Por fim, a terceira e última seção do artigo indica, brevemente, desdobramentos da análise das tensões entre o valor da autonomia e a crítica à opressão considerando as contribuições, e os limites, das abordagens discutidas nas seções anteriores.

\section{Opressão, ressignificação das experiências e "corpo vivido"}

As mulheres são marcadas pelo corpo de maneiras socialmente diversas dos homens. Essa afirmação, desde que mantida assim genérica, pode ser associada amplamente à crítica feminista contemporânea e à própria noção de gênero. Pode corresponder, ainda genericamente, à crítica ao fato de que as mulheres sejam percebidas como o "Outro" dos homens e que essa alteridade seja definida pela oposição entre corpo e razão. A crítica à objetificação das mulheres passa, assim, pelo fato de que o feminino (como oposição binária ao masculino) seja perfilado a partir do olhar dos homens, de seu ponto de vista, sem que isso implique reciprocidade na definição do que caracterizaria as identidades de umas e outros.

Logo no início do primeiro volume d'O segundo sexo, obra de Simone de Beauvoir que, como se sabe, teve forte impacto sobre o debate feminista no século XX, a definição do que significa ser mulher é discutida a partir das relações de poder entre mulheres e homens. A pergunta se apresenta a partir da própria condição das mulheres. Um homem, diz a autora, não precisa se "apresentar como um indivíduo de determinado sexo: que seja homem é natural (...) o homem 
12 BEAUVOIR, 2008a[1949], p. 11 12.

${ }^{13}$ BEAUVOIR, 2008a[1949], p. 12 Em todas as passagens aqui citadas, os trechos da versão portuguesa utilizada pela autora deste artigo foram adaptados para seu uso comum no português do Brasil.

${ }^{14}$ BEAUVOIR, 2008a[1949], p. 211 grifos acrescentados.

${ }^{15}$ BEAUVOIR, 2008a[1949], p. 36

${ }^{16}$ BEAUVOIR, 2008a[1949], p. 35

${ }^{17}$ BEAUVOIR, 2008a[1949], p. 58

${ }^{18}$ BEAUVOIR, 2008a[1949], p. 60 representa ao mesmo tempo o positivo e o neutro". ${ }^{12} \mathrm{E}$ continua:

[...] há um tipo humano absoluto que é o masculino. A mulher tem ovários, um útero; eis as condições singulares que a encerram na sua subjetividade; dizse de bom grado que ela pensa com as glândulas. $O$ homem esquece soberbamente que a sua anatomia também comporta hormônios e testículos. Encara o corpo como uma relação direta e normal com o mundo que acredita apreender sua objetividade, ao passo que considera o corpo da mulher sobrecarregado por tudo o que o especifica: um obstáculo, uma prisão. ${ }^{13}$

Já nessa crítica de Beauvoir, com a qual dialogam análises posteriores, o corpo e a identidade da mulher são ao mesmo tempo apreendidos como dados de sua condição (fisiológica e social, sem que a primeira tenha existência separada da segunda) e como objetos forjados pelo olhar masculino. Um dos problemas centrais a Beauvoir, que atravessa as abordagens feministas de diferentes vertentes, é que as mulheres constituam sua própria percepção, de si e de sua posição do mundo, a partir desse olhar. Ela se preocupa em esclarecer que existem incentivos sociais de diversos tipos para que as mulheres se acomodem à visão masculina e aos interesses masculinos - em 1949, quando o livro foi originalmente publicado, a posição socioeconômica vantajosa dos homens em relação à mulher e o prestígio que o casamento confere a elas foram apontados como os principais incentivos. O "seu ser-paraos-homens" é, assim, elemento essencial de sua condição. No contexto de desigualdades descrito pela autora, "a mulher se conhece e se escolhe, não tal como existe para si, mas tal qual o homem a define". ${ }^{14}$

Mas não é só da perspectiva masculina que o corpo feminino se constituiria como um obstáculo. Embora seja central à singularidade humana - o diálogo com a fenomenologia e com o existencialismo produz as afirmações de que não há consciência sem corpo, ${ }^{15}$ "a presença no mundo implica rigorosamente a posição de um corpo" que é objeto e sujeito, coisa no mundo e ponto de vista sobre o mundo $^{16}-$, a fisiologia feminina parece constituir uma realidade distinta, um peso diferenciado. "A mulher é adaptada às necessidades do óvulo mais do que a ela própria. Da puberdade à menopausa, é o núcleo de uma história que nela se desenrola e que não lhe diz respeito pessoalmente". ${ }^{17} \mathrm{E}$, numa formulação que serve como uma síntese dessa percepção de que o corpo feminino é opressivo, "a mulher, como o homem, é o seu corpo, mas o seu corpo não é ela, é outra coisa". ${ }^{18}$ 
${ }^{19}$ Esse último trecho faz parte da discussão de Simone de Beauvoir sobre a menstruação. A sequencia da reflexão, quando passa à maternidade, aprofunda essa visão da alienação da mulher em relação ao seu corpo. É nesse entendimento que vai-se construindo a correspondência entre espécie, fisiologia e imanência, de um lado, e indivíduo, liberdade e transcendência, de outro. Essa oposição teria um significado distinto para homens e mulheres. Isso permite que Beauvoir assuma, em várias passagens, a visão de MerleauPonty de que somos nosso corpo, de que o corpo é "um esboço provisório" do ser total (referência à Fenomenologia da percepção, em BEAUVOIR, 2008a[1949], p. $60)$, mas diferencie a relação entre corpo e individualidade nas mulheres.

${ }^{20}$ BEAUVOIR, 2008a[1949], p. 63

${ }^{21}$ BEAUVOIR, 2008a[1949], p. 67.

22 BEAUVOIR, 2008a[1949], p. 69

${ }^{23}$ BEAUVOIR, 2008a[1949], p. 68.

${ }^{24}$ BEAUVOIR, 2008b[1949], p. 81
O corpo, portanto, é um fator de sua alienação. ${ }^{19}$

Um dos aspectos que distinguem a mulher do homem é, portanto, sua subordinação à espécie. E é essa compreensão, presente nos trechos citados acima, que vem sendo destacada nas críticas que apontam na análise de Beauvoir a aceitação de uma compreensão convencional da correspondência entre mulher, papéis sociais de gênero e determinantes biológicas.

Pode-se, no entanto, destacar nessa análise o fato de que a existência feminina envolveria, ao mesmo tempo, alienação e recusa à alienação. ${ }^{20} \mathrm{Em}$ sua compreensão, a subordinação à espécie - e, em certo sentido, aos constrangimentos que o próprio corpo imporia - depende de como o corpo é vivido em contextos específicos, isto é, de como a sociedade "regula" as possibilidades dos indivíduos ${ }^{21}$ e de como o "contexto ontológico, econômico, social e psicológico" dá sentido aos "dados da biologia". ${ }^{22}$ Assim, "não é enquanto corpo, é enquanto corpos submetidos a tabus, a leis, que o sujeito toma consciência de si mesmo e se realiza: é em nome de certos valores que ele se valoriza" e a fisiologia não produz valores. ${ }^{23}$ É como "realidade vivida", como corpo "assumido pela consciência" que ele tem peso na definição das experiências e da posição da mulher no mundo.

É a partir desses valores, isto é, das normas e ideologias que regem a relação entre os indivíduos e seu corpo e não de uma essência fundada na natureza da fêmea ou do macho, que Beauvoir expõe uma relação diferenciada entre corpo e autonomia para mulheres e homens. A sociedade, sobretudo a família e os educadores, seria responsável por produzir na mulher um caráter de passividade. Mas, levando em conta essa análise, as ambiguidades ficam mantidas: o fato de que não seja a fisiologia, mas as pressões sociais, que restringem sua liberdade (e seus movimentos) não diminul o peso dos corpos na produção das identidades. A relação entre corpo e resignação, de um lado, e corpo e liberdade, de outro, está largamente presente nessa análise. A experiência da mulher envolve, nas condições sociais descritas, uma relação entre a impotência física e a aceitação de seu lugar na sociedade. "Não ter confiança no corpo é perder confiança em si próprio", envergonhar-se do corpo é parte da renúncia à liberdade e aos prazeres. Os homens, diferentemente, vivenciariam seu corpo como sua expressão objetiva; no homem, "os impulsos eróticos confirmam o orgulho que tira do seu corpo: neste, descobre o sinal da sua transcendência e do seu poder". ${ }^{24}$ Mas o desassossego da mulher em relação ao próprio corpo, assim como o sentimento de impotência, mais uma vez, não são um destino que se desdobra da biologia. No tom característico d'O segundo 
${ }^{25}$ BEAUVOIR, 2008b[1949], p. 82

${ }^{26} \mathrm{MOI}, 1999$, p. 66.

${ }^{27}$ YOUNG, 2005.

\begin{abstract}
${ }^{28}$ Publicada em 2005, a coletânea reúne textos que haviam sido publicados entre 1980 e 2004, em diferentes periódicos ou coletâneas na língua inglesa. Têm em comum, segundo Young, o objetivo de descrever "a subjetividade e a experiência das mulheres como vividas e sentidas na carne" (YOUNG, 2005, p. 7). As expressões "lived body", "embodied experience" e "lived body experience" são recorrentes nos textos da coletânea (YOUNG 2005) e estão sendo aqui traduzidas, respectivamente, como "corpo vivido", "experiência corporificada" e "experiência do corpo vivido".
\end{abstract}

${ }^{29}$ YOUNG, 2005, p. 8. sexo, Beauvoir afirma que "é em grande parte a angústia de ser mulher que corrói o corpo feminino". ${ }^{25}$ Numa leitura simpática ao argumento de Beauvoir e que reforça nele a crítica ao determinismo biológico, pode-se entender que, mesmo com todos esses constrangimentos, as mudanças na posição social dos indivíduos, resultantes de transformações nas relações de poder, permitiriam vivências diferenciadas de si e dos corpos. A análise de Beauvoir levaria ao entendimento de que "uma maior liberdade produzirá novas maneiras de ser mulher, novas maneiras de experienciar as possibilidades do corpo de uma mulher". ${ }^{26}$ Nessa leitura, o corpo é parte da condição da mulher e, como tal, é vivenciado nas relações - menos ou mais opressivas, menos ou mais livres - em que esta se define. As convenções e constrangimentos sociais são vivenciados por indivíduos concretos que, por sua vez, definem-se e tomam forma em relação a elas. Há, assim, uma vivência ativa dos constrangimentos, que em contextos sociais em transformação pode significar uma transformação das identidades que se definem.

É nessa chave que Iris Marion Young ${ }^{27}$ retoma Simone de Beauvoir e o conceito de "corpo vivido" no primeiro capítulo da coletânea On Female Body Experience, intitulado "Lived Body vs. Gender: Reflections on Social Structure and Subjectivity". Nos textos reunidos na coletânea, a análise dos discursos normativos sobre o corpo e a análise das experiências "corporificadas" das mulheres aparecem associadas ao esforço, permanente na obra de Young, de refletir sobre formas estruturais de opressão. ${ }^{28}$

São as tensões e continuidades entre dois esforços, o de analisar criticamente os discursos normativos (a ideologia, as representações hegemônicas) e o de analisar a singularidade das experiências vividas e corporificadas, que mais interessam à discussão feita neste artigo. Young antecipa essas tensões já na apresentação do livro, quando explicita a dupla filiação da abordagem crítica que organiza os textos. De um lado, a tradição fenomenológica existencialista, representada sobretudo por Maurice Merleau-Ponty e Simone de Beauvoir, que ressalta a corporalidade e concretude das vivências - e, portanto, o fato de que não se esgotam nos discursos normativos, sendo a base para uma teoria da subjetividade. De outro, as abordagens críticas representadas, nominalmente, na introdução da coletânea, por Gilles Deleuze, Jacques Lacan, Jacques Derrida, Julia Kristeva, Lucy Irigaray, Michel Foucault e Pierre Bourdieu, previniriam a leitura inocente da fenomenologia como dispositivo crítico que daria acesso a "uma experiência corporificada pura anterior à ideologia e à ciência" -, apontando caminhos para a análise das formas de opressão. ${ }^{29}$ 
${ }^{30}$ YOUNG, 2005, p. 16

${ }^{31}$ YOUNG, 2005, p. 26.

${ }^{32}$ YOUNG, 2005, p. 17. A posição de Young, no entanto, é diferente da de Toril MOI, 1999, com quem dialoga no texto. Para Young, o conceito de "corpo vivido" não deve substituir o de gênero, mas somar-se a ele.
O conceito de "corpo vivido" é definido, a partir de Beauvoir e Merleau-Ponty, como "ideia unificada de um corpo físico agindo e tendo experiências em um contexto sociocultural específico", como "corpo-em-situação". ${ }^{30}$ A tradição fenomenológica existencialista de compreensão do corpo permitiria entendê-lo como convergência entre facticidade e situação. O corpo é o que as relações concretas e o ambiente social permitem que seja, mas ganha existência também à luz dos projetos e formas de atuação dos indivíduos (em relações de engajamento com outros).

O recurso ao conceito de corpo vivido na análise de Young é justificado pela possibilidade que representaria de analisar "como os corpos vivenciam sua posição estrutural", "como os corpos vivenciam suas posições nas estruturas sociais da divisão do trabalho, das hierarquias do poder e das normas da sexualidade". ${ }^{31}$ Permitiria, assim, considerar ao mesmo tempo os constrangimentos estruturais e as reações a esses constrangimentos, isto é, a vivência diferenciada desses constrangimentos e das oportunidades existentes.

Em duas frentes que compõem uma mesma argumentação, a autora relaciona o conceito às noções de gênero e de identidade. No primeiro caso, o entendimento de que o corpo é sempre constituído culturalmente reforçaria uma compreensão do gênero como "hábitos corporais e interações com outros que nós atuamos e experienciamos" . ${ }^{32}$ No segundo, a discussão avança na direção que nos interessa aqui. O conceito de "corpo vivido" permitiria pensar a noção de identidade como correspondente a vivências concretas. Seu mérito seria, nessa abordagem, destacar a identidade como um conjunto de variáveis ou parcelas sobrepostas, mas distintas, da experiência. Em outras palavras, o conceito permitira dar conta da singularidade que constitui as identidades individuais ou subjetivas, sem ignorar que elas se definem apenas em interações sociais concretas e são por elas constituídas. Na exposição da autora,

Se nós conceitualizamos as identidades individuais como constituídas por diversas identidades de grupo - gênero, raça, classe, orientação sexual, e assim por diante - parece haver um mistério sobre como as pessoas são individualizadas e como essas diferentes identidades de grupo se combinam em uma pessoa. Com a ideia de corpo vivido esse quebra-cabeça não se coloca. Cada pessoa é um corpo distinto, com características específicas, capacidades e desejos que são ao mesmo tempo similares e diferentes dos das outras pessoas em determinados aspectos. Ela é nascida em um lugar e tempo particular, é criada

88 Estudos Feministas, Florianópolis, 21 (1): 81-105, janeiro-abril/2013 
${ }^{33}$ YOUNG, 2005, p. 18

${ }^{34}$ YOUNG, 2005, p. 31

${ }^{35} \mathrm{~A}$ distinção entre série e grupo proposta por Sartre na Crítica da razão dialética é fundamental para os argumentos de Young em "Gender as Seriality: Thinking about Women as a Socia Collective“, aqui referido (YOUNG 1997), mas optamos por não incorporá-la a este artigo.

36 YOUNG, 1997, p. 32.

${ }^{37}$ YOUNG, 1997, p. 33 em um ambiente familiar particular, e todos esses têm histórias socioculturais específicas e que se diferenciam da história de outras pessoas de maneiras particulares. ${ }^{33}$

Nessa compreensão, a análise da relação entre os dois termos, gênero e identidade, permitiria justamente levar em consideração como os constrangimentos estruturais dão forma às identidades de gênero sem que, no entanto, sejam capazes de determinar ou totalizar as experiências das mulheres. Nesse sentido, é possível que algumas mulheres transcendam ou escapem, de diferentes maneiras, aos padrões que tipicamente definiriam a feminilidade e que são condicionados pelas estruturas sociais. ${ }^{34}$ Isso não invalida, no entanto, o impacto das situações e definições típicas na construção das identidades. Em outro estudo, Young lançaria mão dos conceitos de "corpo vivido" e de série ${ }^{35}$ para expor essa tensão entre tipicidade e variedade, ou entre as determinações estruturais e as diferentes formas de deslocamento que se impõem sem anulá-las.

A própria noção de identidade, como autopercepção (que se desdobraria do desenvolvimento psíquico dos indivíduos) e como pertencimento consciente a um grupo (em que a percepção do que define o indivíduo se desdobraria em posicionamento políitico), é vista como inadequada porque produziria uma falsa unidade, em um mecanismo de naturalização e de homogeneização que excluiria indivíduos e experiências que destoam das características e padrões de comportamento presumidos. Mas é, além disso, considerada um passo - epistemológica e politicamente - desnecessário para a compreensão dos padrões estruturais de gênero, com as formas de estigmatização e de marginalização que implicam. Assim, "dizer que uma pessoa é uma mulher pode antecipar algo sobre os constrangimentos e expectativas em geral com os quais ela precisa lidar. Mas não antecipa qualquer coisa em particular sobre quem ela é, o que ela faz, como ela vivencia sua posição social" ${ }^{36}$ Em outras palavras, as marcas de gênero não podem ser evitadas, mas o modo como o gênero marca uma vida individual é específico e variável. ${ }^{37}$ Além disso, a relação entre o sexo e outras variáveis e formas de "pertencimento", como classe social, raça, ocupação, pode definir de maneiras variadas o sentido e o peso relativo que o gênero tem para um indivíduo. De modo mais abrangente, os constrangimentos estruturais se impõem, mas o modo como recortam identidades e alternativas não está contido nessa afirmação, ainda que ela seja uma premissa bastante razoável.

Se Young, claramente, assume um foco mais voltado para as estruturas sociais do que para a subjetividade em sua obra, o que os textos publicados em On Female Body 
${ }^{38}$ Esse argumento não retoma diretamente os estudos de James C. SCOTT, 1985 e 1990, mas é certamente marcado por eles. Foise definindo, também, a partir de discussões com Luis Felipe Miguel e das análises presentes em BIROLI, 2011, e MIGUEL e BIROLI, 2011 .

39 Apenas um deles, "Menstrua Meditations", foi publicado pela primeira vez na coletânea On Female's Body Experience, de 2005.

${ }^{40} \mathrm{O}$ objetivo aqui não é buscar pegadas ou o rastro que permitiria chegar a algo como uma visão mais completa de conceitos ou posições abrangentes da autora, mas indicar momentos nessas reflexões em que a tensão estrutura-experiência se coloca ou (supostamente) se resolve. Para uma crítica ao conceito de perspectiva em Young, conferi MIGUEL, 2010.

${ }^{41}$ YOUNG, 2000, p. 136

42 YOUNG, 2000, p. 137

${ }^{43}$ YOUNG, 2000, p. 139.
Experience (e também em Instersecting Voices) parecem mostrar é que há um continuum entre estruturas e vivência subjetiva que é preciso considerar para apreender o funcionamento e os efeitos da opressão. Os padrões que derivam das formas socialmente estruturadas de opressão, sobretudo os padrões das desigualdades que se cristalizam e reproduzem, impõem limites à autonomia dos indivíduos e, portanto, ao modo como vivem e definem seus interesses e projetos. Mas, repetindo de outro modo o que foi dito no parágrafo anterior, esse não é todo o enredo. Ou, para tocar no problema de maneira mais direta, a opressão não define os indivíduos. E, portanto, defini-los como resultantes dela significaria perder de vista, analítica e politicamente, não apenas questões relativas à subjetividade ou à vivência individual das estruturas sociais, mas também fissuras e ruídos na dinâmica de reprodução da opressão e das desigualdades. Ainda que essas fissuras não permitam vislumbrar algo como uma contraofensiva coerente ou orquestrada, o custo de ignorá-las poderia ser, no mínimo, tomar a dinâmica da dominação como mais abrangente, e mais eficaz e onipresente, do que de fato é. ${ }^{38}$

Apesar de essa análise sobre a tensão entre os constrangimentos estruturais e a especificidade das experiências ter, até este momento, retomado especificamente dois livros de Iris Marion Young, publicados em 1997 e 2005, a presença dessa temática na obra da autora certamente ultrapassa esse período. Mesmo que se tomem apenas as duas coletâneas mencionadas, pelo menos seis dos artigos nelas apresentados, que incluem explicitamente essa preocupação, foram originalmente publicados entre os anos de 1980 e $2002 .^{39}$

Em seu esforço para lidar com os problemas relativos à tensão estrutura-experiência, esses textos apresentam pressupostos e abordagens que têm conexões diretas com o conceito de perspectiva social, proposto pela autora no livro Inclusion and Democracy, de 2000, e que tem sido desde então influente na literatura sobre política da diferença e sobre as desigualdades entre os grupos sociais no âmbito da representação e da participação política. ${ }^{40} \mathrm{O}$ conceito de perspectiva social corresponde a posições sociais estruturais, relativas, que produzem experiências particularmente localizadas e um conhecimento específico dos processos sociais. ${ }^{41}$ Corresponde, ainda, a "um conjunto de questões, tipos de experiência e presunções" que são a base para a razão e a compreensão que temos do mundo e de nossa posição nele ${ }^{42}$ e a "um modo de olhar para os eventos sociais, que condiciona mas não determina o que se vê". ${ }^{43}$

A relação entre categorias como gênero, raça e etnicidade, perspectivas e posições estruturais não é direta. 
${ }^{44}$ YOUNG, 2005, p. 18.

${ }^{45}$ Essa expressão é de Nancy FOLBRE, 1994, apud YOUNG, 2005, p. 21.

${ }^{46}$ A noção de "corpo vivido" ponto de partida para o diálogo com Iris M. Young neste artigo assim como a importância de Simone de Beauvoir e da fenomenologia existencialista para as discussões da autora estão presentes, como foi dito, em uma série de textos escritos em diferentes momentos. Se isso denota sua importância para as posições assumidas pela autora indica também que, ao menos de forma direta, ela é localizada - e talvez mesmo marginal. Simone de Beauvoir, muito presente nas discussões dos textos publicados nas coletâneas de 1995 e 2003, está ausente na bibliografia de Justice and the Politics of Difference, publicado em 1990, e de Inclusion and Democracy, publicado em 2000. Nesses dois livros, mas sobretudo no primeiro, o problema da relação entre corpo e opressão está presente, mas Beauvoir não é chamada à discussão. Sartre permanece na bibliografia, nos dois casos, mas tem uma presença pontual (com Réflexion sur la question juive e Critique de la raison dialectique ).
Essas categorias não descrevem parcelas identitárias, pertencimentos ou características que produziriam perspectivas a elas correspondentes, mas seriam uma espécie de atalho para um conjunto de estruturas que posicionam as pessoas. ${ }^{44}$ Sua posição nas estruturas é múltipla justamente porque se define pelo lugar que ocupam em vários espaços institucionais, pela maneira como relações de poder que são multifacetadas - isto é, que definem constrangimentos e oportunidades de maneiras diversas e têm impactos também diversos para os indivíduos, segundo sua história, origem social etc. - as situam. $O$ fato de que a configuração e os pesos de diferentes fatores estruturais sejam variáveis, no entanto, não impede que as estruturas sociais possam ser definidas como "estruturas de constrangimento". ${ }^{45}$ Não há, por assim dizer, neutralidade no modo como essas estruturas definem obstáculos e oportunidades, vantagens e desvantagens. A reprodução das desigualdades e das hierarquias que se cristalizam nas instituições, nos padrões de valoração e de comportamento pode ser tomada como as estruturas em ato, com seus efeitos concretos - e, como se disse antes, diferenciados - sobre os indivíduos.

Mas a razão pela qual se estabelece aqui uma conexão entre o recurso à noção de "corpo vivido" e o conceito de perspectiva social é que, nos dois casos, é ativada, como orientação normativa, uma valorização da experiência em sua especificidade. ${ }^{46} \mathrm{~A}$ análise das formas de opressão tem como um de seus elementos a valorização das posições variadas, com as perspectivas sociais que nelas se definem. A multiplicidade de posicionamentos nas estruturas - mesmo tomando-as como "estruturas de constrangimento" - engendraria experiências politicamente válidas, cujo resgate seria necessário para que as formas de deliberação e representação políitica sejam de fato plurais, mas também para que a compreensão das interações e das relações de poder (e me refiro aqui à operação analítica de levar em conta essas interações) não reproduza a própria dinâmica da opressão, eliminando experiências e vozes. As localizações sociais diversas são, assim, a base para que seja possível obter uma visão mais alargada da sociedade. O conhecimento que encerram e as perspectivas que as singularizam são ao mesmo tempo resultantes dos condicionamentos (e constrangimentos) estruturais e das potencialidades a partir das quais seria possível compreendêlos diferentemente e quiçá redefini-los.

$\mathrm{O}$ artigo "House and Home: feminist variations on a theme", publicado tanto em Intersecting Voices quanto em On Female's Body Experience, é um exemplo de como Young situa essa discussão. A manutenção rotineira da casa, ainda 
47 BEAUVOIR, 2008a[1949]

${ }^{48}$ Lucy IRIGARAY, 1992.

${ }^{49}$ YOUNG, 1997, p. 149-150.

${ }^{50}$ YOUNG, 1997, p. 149. As noções de homemaking e housework não têm correspondentes que as distingam claramente no português. A afirmação, feita pela autora, de que "not all homema-king is housework" precisa da distinção entre cuidado (mais pessoal, que produz identidade e não é apenas a repetição de tarefas alienantes) e trabalho (manuten-ção repetitiva das tarefas domésticas). A distinção entre home e house, lar e casa no português, contribul também para a diferenciação entre algo exterior ao sujeito e algo que constitui sua identidade.

${ }^{51}$ GILLIGAN, 1982, p. 17.

52 Para um mapeamento do debate sobre ética relacional e gênero, cf. Marilyn FRIEDMAN 2003, especialmente a parte II. que tediosa, escravizante ${ }^{47}$ e compulsória na construção das experiências e da identidade de muitas mulheres, ${ }^{48}$ é vista por Young como uma atividade que dá sentido à casa como espaço de preservação - do que me pertence, mas sobretudo da memória, constituindo a casa como um espaço próprio marcado pela história e trajetória das pessoas. ${ }^{49}$ Mas é revelador que a consideração negativa do trabalho doméstico para as mulheres seja vista como um desprezo pela "voz das próprias mulheres" ao "negar inteiramente o valor que muitas dão ao cuidado com a casa". ${ }^{50}$

As experiências tipicamente femininas - ainda que o típico seja o resultado de convenções que precisam ser questionadas para que as relações de gênero se organizem de maneira menos desvantajosa para as mulheres - são consideradas, nesse caso, como produtoras de identidades que não podem ser negligenciadas. Num passo adiante, $\mathrm{o}$ chamado pensamento maternal considera que um dos objetivos da crítica feminista é justamente resgatar essas vozes, que dariam acesso a uma sensibilidade e a uma ética diferenciada. O cuidado com a casa, como o cuidado com os mais vulneráveis, aparece como a matéria de experiências que fundam perspectivas excluídas pelos valores masculinos. Em um exemplo dessa visão, que está na base da relação entre experiências tipicamente femininas e ética relacional (ou do cuidado), Carol Gilligan afirmaria que a "sensibilidade às necessidades dos outros e a presunção da responsabilidade por cuidar permite que as mulheres considerem outras vozes, e não apenas a sua própria, e incluam no seu julgamento outros pontos de vista". ${ }^{51}$ Assim, as mulheres teriam como um diferencial (positivo do ponto de vista moral e ético) a preocupação com as relações e a centralidade da sua responsabilidade para com os outros. ${ }^{52}$

O nó, por assim dizer, é como distinguir, nessas bases, a especificidade da experiência, isto é, a configuração subjetiva das identidades diferenciadas - no caso, das muIheres imersas em papéis e atividades tipicamente femininos - e as restrições às experiências, que resultam de formas sistemáticas de opressão. O problema que se configura é, portanto o das continuidades entre as experiências subjetivas, que constituem identidades que são caras aos indivíduos, e os constrangimentos a experiências e papéis diversos, que potencialmente ampliariam o leque das alternativas e tornariam mais autônomo o processo de produção das identidades.

Opressão, descoberta das experiências e "conhecimento vivido"

As experiências possíveis estão diretamente relacionadas à posição social ocupada pelos indivíduos. Essa 
${ }^{53}$ Conferir a crítica de Susan Okin ao chamado pensamento maternal e à distinção entre ética do cuidado e justiça (OKIN, 1989a e 1989b).

${ }^{54}$ FOUCAULT, 1995[1979].

${ }^{55}$ Louis ALTHUSSER, 2003[1971], p 104.

${ }^{56}$ FRIEDAN, 1997[1963]. compreensão não está ausente das análises antes mencionadas, mas ganha, nelas, um sinal positivo. Ela é, no entanto, uma das bases para a crítica à valorização da experiência, no sentido mencionado na seção anterior, em análises que enfatizam o fato de que as experiências não são definidas num âmbito subjetivo em que razão ou vontade se imporiam livremente.

As críticas à valorização da singularidade feminina jogam luz, por exemplo, sobre o fato de que a vivência específica das mulheres, em papéis convencionais de gênero, corresponde ao fortalecimento de determinadas características que não são em si negativas, mas que implicam a negação ou enfraquecimento de características e de projetos de vida alternativos. A valorização da maternidade, por exemplo, não corresponde nesse sentido à atenção a experiências individuais, mas a padrões que organizam as experiências de um grupo social, no caso as mulheres, e que vêm sendo consolidados em detrimento de outras possibilidades de organização da vida. Em outras palavras, a "diferença" que a posição social fornece corresponde a desvantagens relativas que colaboram justamente para manter essas posições sociais tais como estão convencionalmente definidas e hierarquizadas. ${ }^{53} \mathrm{O}$ que se passa, então, é algo que poderia ser pensado como a vivência singular dos padrões de opressão - que organizam representações do feminino e potencializam formas de autoidentificação, de identificação dos outros e pelos outros. A "diferença" corresponde, portanto, a padrões que caracterizam e identificam na mesma medida em que constrangem e hierarquizam.

Características como a afetividade, o "talento" para dedicar-se a outrem e cuidar das crianças ou mesmo a beleza, para citar apenas alguns exemplos, carregam em si ambiguidades que são características do exercício da opressão ou, no sentido de Michel Foucault, ${ }^{54}$ da positividade do poder. A afirmação de que os sujeitos são constituídos pela sua sujeição ${ }^{55}$ pode ser mobilizada para explicar o caráter dessas ambiguidades, compreendendo que a identidade subjetiva e a alienação constituem-se de uma mesma matéria (no caso de Foucault, as formas de subjetivação que materializam práticas e discursos de verdade ativos em um dado momento; no caso de Althusser, a dinâmica pela qual a ideologia interpela os indivíduos e os constitui como sujeitos).

Na crítica feminista, há análises bastante sensíveis a essas ambiguidades. Betty Friedan ${ }^{56}$ dá o nome de "mística feminina" ao estímulo, difuso porém efetivo, para que as mulheres se dedicassem aos cuidados domésticos com a casa e os filhos, transformando a dedicação a essas atividades em seu valor (afetivo, social) e sua identidade. A autora expõe justamente as ambiguidades nos relatos que 
${ }^{57}$ FRIEDAN, 1997[1963], p. 100.

${ }^{58}$ FRIEDAN, 1997[1963], p. 91. Friedan relata as observações de editores de revistas femininas sobre quem seriam as mulheres que constituem seu público e observa que contribuem para moldar as identidades das mulheres ao presumirem que são "interessadas apenas na família e no lar" vivendo um mundo feminino à parte, que consistiria em "uma paixão, um papel, uma ocupação" (FRIEDAN, 1997[1963], p. 84-85)

${ }^{59}$ WOLF, 2002[1991], p. 14

${ }^{60}$ WOLF, 2002[1991], p. 14

${ }^{61}$ WOLF, 2002[1991], p. 271

${ }^{62}$ WOLF, 2002[1991], p. 270. mulheres estadunidenses de classe média, moradoras dos cinturões residenciais suburbanos em expansão nos Estados Unidos das décadas de 1950 e 1960, fazem de sua própria experiência. Por outro lado, mostra como as mulheres são interpeladas por uma série de representações de gênero, presentes na mídia e em discursos de especialistas. Elas "dão forma à realidade que distorcem", ${ }^{57}$ celebrando como valor máximo e atividade satisfatória a busca de vivenciar plenamente a própria feminilidade. ${ }^{58}$ Quase três décadas depois, Naomi Wolf diria, numa referência ao livro de Betty Friedan e ao impacto do chamado feminismo de segunda geração, que as mulheres se libertaram da mística feminina da domesticidade, mas foram tomadas pela mística da beleza. A domesticidade daria lugar a uma beleza domesticada, que prescreve comportamentos e não aparências ${ }^{59}$ e que repõe o trabalho de "coerção social" antes feito pela valorização da maternidade, da castidade e da passividade, impondo um retrocesso à conquista de maior igualdade entre mulheres e homens e às ideias $e$ práticas feministas. ${ }^{60}$

O caráter de denúncia desses dois textos se divide em duas frentes, sempre relacionadas nos argumentos das autoras. Uma delas é que as mulheres estão sendo interpeladas a assumir uma identidade que é socialmente valorizada, porém restringe suas experiências, seu desenvolvimento e as chances de que ocupem posições e desenvolvam talentos de maneira mais igualitária em relação aos homens. A representação da feminilidade que está na base da identidade de muitas mulheres corresponde a desvantagens - no âmbito pessoal-afetivo e no âmbito público, profissional e político. Nesse sentido, seria possível estabelecer uma relação bastante direta entre identidades, preferências aprendidas e opressão. Voltamos ao nó antes anunciado: como distinguir, então, entre as experiências e perspectivas específicas (no caso, das mulheres) e a vocalização de preferências que expressam padrões socialmente reproduzidos e desvantajosos, mas moldam comportamentos e formas eficazes de autoidentificação?

No último capítulo do livro de Naomi Wolf, intitulado "Beyond the Beauty Myth", a autora, depois de ter discutido demoradamente o mito da beleza e seus impactos na construção da identidade das mulheres, diria que se trata de um problema de "falta de escolha". ${ }^{61}$ Perguntas como "o que é uma mulher?", "ela é feita do que é feito dela?", "sua vida e suas experiências têm algum valor?"62 convergem então, nos argumentos da autora, para a distinção entre escolhas reais e coerção, liberdade e compulsão. O problema complexo da construção das identidades com os recursos que as relações de opressão - ou a ideologia, em Wolf - fornece

94 Estudos Feministas, Florianópolis, 21 (1): 81-105, janeiro-abri//2013 
${ }^{63}$ WOLF, 2002[1991], p. 273. ${ }^{64}$ WOLF, 2002[1991], p. 274, grifos acrescentados.

${ }^{65}$ Os exemplos no capítulo final do livro são abundantes. Caricata, a visão de que a beleza, assim como a sexualidade, pode ser livre ou controlada expõe um elemento importante no que talvez possa ser considerado o senso comum corrente sobre a autonomia: devemos nos definir a partir de nós mesmos, e não de constrangimentos externos. Os recursos do self, ou os recursos que podemos descobrir e compartilhar quando nos distinguimos do que a dominação faz de nós, permitiriam uma identidade fundada em práticas voluntárias e, avançando um pouco mais nessa visão, espontâneas - isto é, não moldadas pela ideologia. No que talvez seja o ápice dessa visão em um livro que, destaco, teve sua importância na crítica às formas contemporâneas de controle das mulheres, Wolf diz que "o problema com os cosméticos existe somente quando as mulheres se sentem invisíveis ou inadequadas sem eles. O problema com os exercícios físicos existe somente se as mulheres se odeiam quando não o fazem. Quando uma mulher é forçada, para adornar-se, a comprar um brinco [...] é quando a 'beleza' machuca" (WOLF, 2002[1991], p. 273).

${ }^{60}$ Carole PATEMAN, 1985[1979] 1989. A discussão sobre consentimento em Pateman bem mais complexa do que a indicação feita aqui. A crítica ò convivência entre igualdade formal e desigualdades, assim como a crítica às teorias contratualistas e ao individualismo abstrato, são elementos centrais à análise do voluntarismo. Além disso, Pateman não se limita a indicar que 0 consentimento voluntário é limitado pelas desigualdades, mas coloca em questão um framing que pressupõe, segundo ela, um (mais fraco) consentindo ou não a um outro (mais forte). Seria preciso acaba desaguando em uma visão voluntarista e mesmo simplista das escolhas que podem ser feitas se nos distinguimos do mito da beleza e afirmamos "identidades sólidas como rochas"63. Olhando umas para as outras, isto é, destacando suas experiências compartilhadas e não as imagens que a indústria da beleza coloca em circulação, seria possível estabelecer outras referências ou outro "ponto de partida" para a expressão do self: "as mulheres estarão livres do mito da beleza quando pudermos escolher usar nossos rostos e roupas e corpos como simplesmente uma das formas de autoexpressão entre um leque amplo delas". ${ }^{64}$

A definição do que são escolhas livres de coerção é, no entanto, bem mais complexa do que as chamadas de Wolf à reação contra o mito da beleza permitem supor. ${ }^{65} \mathrm{Nova}-$ mente, tomada em sua complexidade, a compreensão das preferências como adaptativas ou aprendidas acrescentaria matizes à dualidade entre escolhas autônomas e coerção.

Um dos problemas que essa reflexão expõe diz respeito à função ideológica das noções de escolha e consentimento que são caras à tradição liberal. Grosso modo, correspondem ao ideário que define como legítimas as obrigações que correspondem a auto-obrigações, dentro dos limites estabelecidos pela reciprocidade entre indivíduos livres e iguais, que seria característica da norma liberal. O que confere legitimidade às relações (entre indivíduos adultos) é, nesse mesmo sentido, o consentimento voluntário. Mas quais são as condições necessárias para que ele possa de fato existir? A crítica, nesse caso, expõe as ambiguidades e limites que as desigualdades efetivamente existentes colocam à ideia de consentimento voluntário, assim como à definição das escolhas que são realizadas autonomamente - mesmo quando formalmente os direitos e a autonomia dos indivíduos são igualmente estabelecidos. ${ }^{66}$

Catherine A. Mackinnon é, possivelmente, a teórica feminista que procurou enfrentar mais diretamente o problema da produção da identidade feminina por meio de uma crítica direta ao voluntarismo e a uma teoria individualista abstrata da formação das preferências. ${ }^{67}$ Sua abordagem, mas também sua atuação como jurista nos movimentos antipornografia e de criminalização do assédio sexual nos Estados Unidos, explicitam essa posição. ${ }^{68}$ Pode-se dizer que contêm, abordagem e atuação, uma posição-limite nesse debate: as experiências femininas em sociedades nas quais persistem relações de gênero assimétricas equivalem, para a autora, a uma percepção mistificada de si. A relação constitutiva entre sexualidade e dominação consolida-se na esfera das relações pessoais e íntimas em um continuum com as divisões que organizam a vida pública, as leis e as instituições. 
encontrar outro modo de tratar da relação que se constitui da concordância entre dois indivíduos em condições de igualdade, outro vocabulário que permitisse descolar-se da ideia e consentimento (PATEMAN, 1989, p. 84).

67 MACKINNON, 1987 e 1989.

${ }^{68} \mathrm{O}$ debate sobre pornografia, no âmbito da literatura feminista, é variado e apresenta contribuições bastante interessantes para pensar o problema da autonomia. Conferir, entre outras, Drucilla CORNELL, 2000, e Pamela GIBSON, 2004[1993]

${ }^{69}$ MACKINNON, 1989, p. 114.

${ }^{70}$ MACKINNON, 1989, p. 90.

${ }^{71}$ MACKINNON, 1989, p. 94-95.

72 MACKINNON, 1989, p. 89-91.
Um dos problemas centrais, para Mackinnon, é que as mulheres não se definirão como indivíduos (que optam, que consentem ou recusam, que têm autonomia sobre seu corpo), e não serão assim consideradas enquanto a perspectiva masculina, dominante, constituir o Estado e a indústria da cultura, os referenciais objetivos para verificação e julgamento da realidade e as expectativas e sentimentos subjetivos das próprias mulheres:

A perspectiva que se define a partir da posição masculina impõe a definição da mulher, envolve seu corpo, configura confusamente suas falas e descreve sua vida. A perspectiva masculina é sistêmica e hegemônica. [...] Porque ela é o ponto de vista dominante e define a racionalidade, as mulheres são levadas a ver a realidade em seus termos, embora isso negue seu ponto de vista como mulheres uma vez que contradiz pelo menos parcialmente sua experiência vivida, particularmente a experiência da violação por meio do sexo. Mas, amplamente, o conteúdo do significado de "mulher" de um ponto de vista masculino é o conteúdo que define as vidas das mulheres. ${ }^{69}$

A tomada de consciência que é a base para a transformação dessa posição subordinada dependeria, assim, da ressignificação das experiências vividas, sobretudo daquelas ocultas atrás das fronteiras estabelecidas pelos valores liberais da privacidade e da liberdade. A autora dedica parte importante de sua discussão no livro A Feminist Theory of the State aos grupos de mulheres nos quais o compartilhamento da experiência vivida permitiria atingir um "conhecimento vivido da realidade social de ser mulher". ${ }^{70} \mathrm{O}$ processo descrito por Mackinnon envolve o recurso às experiências comuns às mulheres, que dariam acesso à "experiência vivida", isto é, a experiências comuns que se tornam visíveis, permitindo a transposição de uma condição de alienação (visão de si a partir de um ângulo de visão masculino) em direção à consciência da própria posição social. ${ }^{71}$ Há pelo menos dois momentos, interligados, que definem esse processo: a descoberta do que é comum às mulheres e a compreensão de que foram, na condição de mulheres, sistematicamente privadas de um "self". É, assim, o reconhecimento dessa privação, considerada a base da socialização feminina, que permitiria construir suas identidades em outras bases, isto é, construí-las autonomamente. ${ }^{72}$

A compreensão que cada mulher tem de si mesma precisa ser modificada. Mas é a tomada de consciência das experiências compartilhadas pelas mulheres, como um grupo social historicamente subordinado aos homens, que permitiria passar do descontentamento e do mal-estar com a própria 
${ }^{73}$ MACKINNON, 1989, p. 86

${ }^{74}$ MACKINNON, 1989, p. 91.

${ }^{75}$ MACKINNON, 1989, p. 96.

${ }^{76}$ MACKINNON, 1989, p. 101.

77 MACKINNON, 1989, p. 102. condição a reivindicações baseadas em uma perspectiva identitária de grupo. O que é relevante, neste ponto, é que essa identidade corresponde ao reconhecimento da privação que se efetua em benefício de um outro grupo social, no caso o dos homens. ${ }^{73} \mathrm{O}$ "conhecimento vivido" das mulheres é, assim, o reconhecimento de que sua subjetividade lhes vem sendo negada, de que sua identidade vem sendo invalidada de diferentes formas.

Mackinnon recorre, frequentemente, ao que poderia ser chamado de um aprendizado orientado, porém incompleto, das preferências. A identidade das mulheres se constituiria, sobretudo, a partir da perspectiva masculina. A própria definição de mulher (socialmente abrangente, mas também fundamental e íntima) está naquilo que lhe é, ao mesmo tempo, exterior e fundamental, desvantajoso e central à sua identidade. O mal-estar relacionado a essa posição é revelador de uma fissura na dominação. É uma espécie de falha na socialização das mulheres que produz o mal-estar e permite a crítica a sua condição subordinada, uma vez que o principal efeito dessa socialização seria justamente retirar às mulheres a possibilidade de se construírem como indivíduos autônomos - isto é, indivíduos cujas identidades e escolhas derivariam da sua própria posição e dos seus sentimentos, e não da perspectiva masculina. Essa fissura ou falha não é, em si, a garantia de uma consciência (da crítica com base no reconhecimento de sua posição como grupo), mas é o que torna possível a descoberta de que as identidades que lhes foram impostas são convencionais, e não naturais. Estabelece-se, então, uma nova relação com as experiências vividas, "uma percepção experienciada de como as coisas vieram a ser como são e de que podem ser mudadas". ${ }^{74}$ Nesse sentido, a conscientização é um processo coletivo que equivale a um "reordenamento daquilo que toda mulher 'sabe' porque ela viveu", ${ }^{75}$ mas que não corresponde ao conhecimento dos "fatos objetivos" porque demanda justamente o conhecimento de que poderia ser de outra maneira. ${ }^{76}$ A tensão entre preferências aprendidas e superação da condição de dominação se estabelece como uma antinomia que produz, potencialmente, a superação de um dos termos que a fundou:

\begin{abstract}
A percepção de que as mulheres em grande medida reconhecem a si mesmas de modo estereotipado, de fato sentem necessidades que foram encorajadas a sentir, de fato sentem-se satisfeitas das maneiras esperadas, frequentemente de fato escolhem aquilo que thes foi prescrito, torna possível a percepção de que as mulheres ao mesmo tempo não reconhecem a si mesmas dessa forma, não sentem e não escolheram este lugar. ${ }^{77}$
\end{abstract}

Estudos Feministas, Florianópolis, 21(1): 81-105, janeiro-abril/2013 
${ }^{78}$ MACKINNON, 1989, p. 104.

79 MACKINNON, 1989, p. 94

${ }^{80}$ Por exemplo em MACKINNON 2005, e em MACKINNON e DWORKIN, 1997.

${ }^{81}$ MACKINNON, 1989, p. 94.

${ }^{82}$ MACKINNON, 1989, p. 124.

${ }^{83}$ MACKINNON, 1989, p. 147.
O feminismo, associado ao compartilhamento das vivências comuns entre as mulheres, permitiria, assim, entender que um dos principais efeitos da dominação masculina é o que a autora chama de uma "distorção do self". ${ }^{78}$ A descoberta de si é a descoberta dessa distorção.

O problema das escolhas feitas pelos indivíduos em contextos em que as desigualdades e assimetrias efetivas são acentuadas torna-se, assim, bastante complexo. De um lado, há o reconhecimento de que as mulheres de fato "escolhem" formas de vida que reproduzem, mesmo - e principalmente - em suas relações mais íntimas, as estruturas de dominação e submissão que caracterizam toda a ordem pública. ${ }^{79}$ Há, desse ponto de vista, uma relação intrincada, e contínua apesar de envolver tensões relevantes, como se viu, entre a opressão sofrida pelas mulheres e identidades que podem ser caras às próprias mulheres. Essa é uma das razões que levam a autora a defender uma forte atuação do Estado, normativa e punitiva, na vida privada e íntima, nas condutas sexuais e nas representações dos papéis sexuais pela indústria do entretenimento.$^{80} \mathrm{~A}$ socialização leva a escolhas mistificadas e sua superação depende, ao mesmo tempo, do acesso das mulheres a suas experiências comuns e do controle de formas práticas e simbólicas de violência e de reprodução do status quo da dominação.

Para nossa discussão neste artigo é fundamental a compreensão da autora de que "cada mulher, ao seu modo", reproduz - e pode mesmo fazer a opção por reproduzir - as relações estruturais de dominação, que a colocam numa posição subordinada e vulnerável. ${ }^{81} \mathrm{~A}$ autora não está falando de mulheres que não têm alternativas, comparativamente com outras que as teriam, mas de uma estrutura social na qual a socialização levaria os indivíduos (no caso, as mulheres) a escolher ser aquilo que se pretende e se presume, de uma perspectiva dominante (no caso, a dos homens), que sejam. A cumplicidade da mulher com sua condição não contradiz o fato de que essa condição seja fundamentalmente inaceitável. E isso se dá justamente porque a alternativa das mulheres, nessas condições, é tornarem-se pessoas que "escolhem livremente papéis femininos". ${ }^{82}$ É assim que um dos aspectos centrais à análise de Mackinnon se estabelece: a dominação sexualizada, por exemplo, é vivida como sexo. A dominação é assim erotizada, e não o sexo propriamente dito..$^{83}$

Pode-se, nesse ponto, ler essa análise como uma explicitação do que Pierre Bourdieu entende como sendo um dos efeitos principais da dominação, a harmonização entre uma dada ordem social e as disposições dos indivíduos, com a incorporação da lógica da própria dominação ao mobilizar como princípios que permitem o 
${ }^{84}$ BOURDIEU, 2001[1997], p. 166 , grifo no original.

${ }^{85}$ BOURDIEU, 2001[1997], p. 169. Essa compreensão, e os conceitoschave que the dão sustentação na obra de Bourdieu, de habitus, illusio e doxa, estão presentes também no ensaio em que o autor analisa a "dominação masculina" (BOURDIEU, 2005[1998]). Nele, as observações sobre o habitus feminino correspondem à incorporação, pelas mulheres, das perspectivas dominantes em sociedades estruturadas a partir da perspectiva masculina, reproduzindo assim a posição que lhes é reservada nessas sociedades. "As próprias mulheres aplicam a toda a realidade $\mathrm{e}$, particularmente, às relações de poder em que se vêem envolvidas esquemas de pensamento que são produto da incorporação dessas relações de pode e que se expressam nas oposições fundantes da ordem simbólica" (BOURDIEU, 2005[1998], p. 45)

Essa análise do autor recebeu muitas críticas, sobretudo de teóricas feministas, como se pode verificar em YOUNG, 2005, p. 26 , e MOI, 1999, p. 264-299, para mencionar autoras já discutidas neste artigo.

${ }^{86}$ MACKINNON, 1989, p. 94

${ }^{87}$ MACKINNON, 1989, p. 124.

${ }^{88}$ MACKINNON, 1989, p. 104.

${ }^{89} \mathrm{~A}$ autora estabelece um paralelo entre a tomada de consciência das mulheres em sociedades dominadas pelos homens e a tomada de consciência do proletariado nas sociedades capitalistas (MACKINNON, 1989, especialmente nas páginas 103 e 104). conhecimento (de si, dos outros e das relações e posições nessa ordem) aqueles que de fato correspondem ao reconhecimento dessa mesma ordem. $O$ efeito de doxa, do reconhecimento do mundo a partir das categorias que esse mundo tornou disponível, dá, assim, um papel central às disposições adquiridas, à "condicionabilidade como capacidade natural de adquirir capacidades não naturais, arbitrárias". ${ }^{84}$

As disposições correspondem, assim, a uma compreensão prática da própria posição no mundo, e do mundo tal como vivenciado a partir dessa posição. ${ }^{85}$ É justamente nesse sentido que, voltando a Mackinnon, as escolhas orientadas e aprendidas não se restringem a orientações embotadas pela dominação. A perspectiva masculina, diferentemente da feminina, também é um produto das formas arbitrárias de classificação que organizam o mundo e, nele, as posições relativas dos indivíduos. Mas coincide com a posição real dos homens em um mundo cujos termos - valores, comportamentos, instituições - foram por eles definidos. Avançando no modo como essas diferentes posições se traduzem em relações de dominação, a questão, diz Mackinnon, não é que os homens estejam numa posição em que necessariamente tratarão mal as mulheres, mas que é sua escolha tratá-las bem ou mal, ${ }^{86}$ em um mundo no qual eles são sujeitos. ${ }^{87}$

Entre os problemas que essa análise coloca está a percepção, simultânea, das mulheres como indivíduos privados de um "self" autônomo, da própria definição de mulher como efeito da dominação, mas também das experiências coletivas dessa condição, isto é, do seu compartilhamento como a base para a ressignificação das identidades das mulheres e das relações de gênero. O caráter comum das experiências revelaria, ao mesmo tempo, a imposição da perspectiva masculina como total (a ilusão em sua materialidade) e o terreno a partir do qual as mulheres podem ser vistas não como o negativo do homem, mas como portadoras de uma perspectiva específica - que, vale repetir, só se faz presente quando se constata a desigualdade social entre os sexos ${ }^{88} \mathrm{~A}$ confrontação com o poder masculino seria, ao mesmo tempo, um reconhecimento de que ele é "total" porque define o mundo e os critérios que permitem julgar a adequação dos comportamentos no mundo por ele definido - e um reconhecimento de que ele é uma ilusão, uma mistificação. ${ }^{89}$ A tomada de consciência, assim definida, permitiria uma aproximação crítica da imagem fraturada e alienada das mulheres e uma percepção que antecipa, como potenciais, relações transformadas e igualitárias, que posicionariam as mulheres como sujeitos na construção de suas identidades e na definição das suas preferências. 


\section{A crítica feminista e as tensões entre autonomia e opressão}

Há alguns aspectos em comum entre as abordagens presentes nas duas seções anteriores. A afirmação feita por Simone de Beauvoir de que "toda a história das mulheres foi feita pelos homens" 90 orientava a crítica para algo que estaria amplamente presente no feminismo posteriormente: os valores tidos como universais são na realidade masculinos e as experiências das mulheres vêm sendo codificadas (e julgadas) a partir deles, isto é, pelos homens. A crítica aos valores universais traz como contraponto, nas abordagens discutidas neste artigo, as perspectivas das mulheres. E a constatação de que essas perspectivas não puderam impor-se como tal, isto é, de que as vozes das mulheres não foram ouvidas, está presente em abordagens que procuram, de maneiras diferentes, "resgatar" essas vozes e expor as fissuras existentes na dominação. Por isso é tão importante, para essas análises, explicitar que a dominação não totaliza as experiências - ou, pelo menos, que há a possibilidade de conhecê-las de outro modo ao considerálas como experiências compartilhadas por um grupo social. Mas essa constatação, de que houve e há obstáculos para que as perspectivas das mulheres se afirmem, está presente, também, na consideração de que as identidades assim constituídas tendem a reproduzir padrões convencionais que, por sua vez, justificam o status quo e as posições hierarquizadas que os indivíduos nele ocupam.

A crítica aos valores universais ultrapassa, no entanto, o próprio feminismo. É justamente a radicalidade dessa crítica que coloca a teoria política feminista em posição de destaque na teoria crítica contemporânea. $O$ fato de que uma dada ordem social produza, ao mesmo tempo, normas, instituições, comportamentos e identidades não é um problema novo para a teoria política, pelo contrário. Mas o reconhecimento de que formas efetivas de opressão convivem com direitos universais, restringindo as experiências e escolhas de parte dos indivíduos, é elevado, pela teoria política feminista, a problema prioritário para as teorias críticas. E um dos desafios colocados pelas abordagens aqui apresentadas é que a crítica deve enfrentar, simultaneamente, o problema da exclusão das perspectivas desses indivíduos sob os véus fundidos da universalidade (como norma) e da opressão (como realidade, muitas vezes velada, mas produtiva) e o problema de que os próprios indivíduos que são por ela colocados em posição de desvantagem colaborem para a reprodução de uma ordem opressiva. 
Os conceitos de "corpo vivido" e de "conhecimento vivido" permitiram, neste artigo, percorrer matizes presentes em abordagens que procuram, justamente, dar conta desses dois problemas. Há, nelas, um esforço para levar em consideração os dois termos, que podem ser definidos como o da autonomia e o da opressão, como vem sendo colocado desde o início neste artigo, ou como o da subjetivação e o da alienação, termos que também perpassaram, ainda que com menos frequência, as discussões feitas aqui. No primeiro eixo, a ênfase nas formas de ressignificação da experiência expõe a vivência concreta e diferenciada das relações de opressão. Tem relevância, epistemológica e politicamente, o fato de que a dominação não totaliza as experiências dos indivíduos e que, portanto, há formas de ação e de autoidentificação que são, de certo modo, distintas dos padrões convencionalmente dispostos. Nas palavras de Toril Moi, em sua análise da influência da fenomenologia existencialista sobre Simone de Beauvoir, embora as normas sociais sejam de importância crucial para a formação da subjetividade de uma dada pessoa, "uma análise dessas normas e formas de regulação não será capaz de explicar por ela mesma a experiência vivida dessa pessoa". ${ }^{91}$

No segundo eixo, diferentemente, a ênfase recai nos limites para que exista, de fato, uma experiência fundada em categorias e possibilidades distintas daquelas que são dispostas pela própria dinâmica da opressão. A crítica social, nesse sentido, teria como tarefa crucial "desvendar" a base restritiva da constituição das identidades dos sujeitos, para que não contribuam para a sua própria dominação. Mas isso não significa que as possibilidades de ressignificação da experiência estejam sendo excluídas ou negadas. Pelo contrário, a noção de "conhecimento vivido", em Catharine Mackinnon, expõe justamente o processo por meio do qual as experiências são compartilhadas e ressignificadas. Corresponde, no entanto, a um desvendamento que permite vislumbrar, sob o véu (novamente, o véu fundido da universalidade e da opressão, na metáfora utilizada há pouco), a distorção do "self". É justamente o reconhecimento, e a denúncia, dessa distorção e dos prejuízos por ela causados nos indivíduos assim posicionados que permitiria a construção de identidades autonomizadas.

Nesse ponto, pode-se reforçar a distinção entre o entendimento de que há experiências que, de algum modo, seriam preservadas sob o véu da opressão e o entendimento de que é preciso revelar as experiências compartilhadas da opressão, que teriam de ser assim significadas para que possam ser ressignificadas. Há, potencialmente, nas análises aqui trabalhadas na primeira seção e sobretudo a partir de 
Iris Marion Young, o reconhecimento e valorização de experiências que não estariam contidas na dominação e que poderiam ser, assim, reveladoras da agência de indivíduos "dominados" - naquilo que escapa justamente aos padrões e moldes socialmente estabelecidos, com seus efeitos restritivos. $O$ que diferencia essa abordagem da de Catharine A. Mackinnon, também central às reflexões aqui desenvolvidas, é que nesta última a construção de identidades autônomas depende, necessariamente, do reconhecimento de que o que somos contém muito do que precisa ser reconhecido como exterior para que sejam possíveis, ao mesmo tempo, perspectivas coincidentes com nossa real posição na atual ordem social e relações de poder transformadas, igualitárias.

A compreensão de como se definem as identidades e as preferências é um problema central para a crítica da convivência entre democracia e opressão, entre liberdades iguais e formas sistemáticas e violentas de restrição às experiências de parte dos indivíduos nas sociedades organizadas com base em valores e instituições liberais. Há matizes que precisam ser considerados para se tomar esse problema em sua complexidade, compreendendo de forma mais adequada a formação das preferências, tema fundamental não apenas para o feminismo mas também para toda a crítica voltada para as modalidades e impactos das desigualdades nas democracias contemporâneas. Este texto procurou contribuir para a superação da dicotomia entre a formação autônoma das identidades e a determinação das experiências pelas relações de opressão, dando passos em direção a uma compreensão mais matizada e complexa da produção das preferências e das identidades em contextos desiguais.

\section{Referências}

ALTHUSSER, Louis. Aparelhos ideológicos do Estado. 9. ed. Rio de Janeiro: Editora Graal, 2003[1971].

BADINTER, Elizabeth. O amor incerto: história do amor maternal do século XVII ao século XX. Lisboa: Relógio D’Água, 1985[1980].

BEAUVOIR, Simone. O segundo sexo. v. 1. Lisboa: Bertrand Editores/Quetzal Editores, 2008a[1949].

. O segundo sexo. v. 2. Lisboa: Bertrand Editores/Quetzal Editores, 2008b[1949].

BIROLI, Flávia. "Mídia, tipificação e exercícios de poder: a reprodução dos estereótipos no discurso jornalístico". Revista Brasileira de Ciência Política, n. 6, p. 71-98, 2011.

BOURDIEU, Pierre. Meditações pascalianas. Rio de Janeiro: Bertrand Brasil, 2001[1997]. 
A dominação masculina. 4. ed. Rio de Janeiro: Bertrand Brasil, 2005[1998].

COHEN, Jean L. "Rethinking Privacy: Autonomy, Identity, and the Abortion Controversy". In: WEINTRAUB, Jeff, and KUMAR, Krishan (eds.). Public and Private in Thought and Practice: Perspectives on a Grand Dichotomy. Chicago: The University of Chicago Press, 1997. p. 133-165.

CORNELL, Drucilla. Feminism \& Pornography. Oxford: Oxford University Press, 2000.

ELSHTAIN, Jean Bethke. Public Man, Private Woman: Women in Social and Political Thought. Princeton: Princeton University Press, 1981.

FOLBRE, Nancy. Who Pays for the Kids? Gender and the Structures of Constraint. New York: Routledge, 1994.

FOUCAULT, Michel. "Verdade e poder". In: Microfísico do poder. Rio de Janeiro: Edições Graal, 1995[1979]. p. 1-14.

FRASER, Nancy. "Beyond the Master/Subject Model: On Carole Pateman's The Sexual Contract". In: ___. Justice Interruptus: Critical Reflections on the "Postsocialist" Condition. New York: Routledge, 1997. p. 225-235.

FRIEDAN, Betty. The Feminine Mystique. New York/London: WW Norton, 1997[1963].

FRIEDMAN, Marilyn. Autonomy, Gender, Politics. Oxford: Oxford University Press, 2003.

GIBSON, Pamela Church (ed.). More Dirty Looks: Gender, Pornography and Power. London: British Film Institute, 2004[1993].

GILLIGAN, Carol. In a Different Voice: Psychological Theory and Women's Development. Cambridge, MA: Harvard University Press, 1982.

IRIGARAY, Lucy. Ethics of Sexual Difference. Ithaca: Cornell University Press, 1992.

MACKINNON, Catharine A. Feminism Unmodified. Cambridge, MA: Harvard University Press, 1987. . Toward a Feminist Theory of the State. Cambridge, MA: Harvard University Press, 1989. Women's Lives, Men's Laws. Cambridge, MA: Harvard University Press, 2005.

MACKINNON, Catharine A., and DWORKIN, Andrea (eds.). In Harm's Way: The Pornography Civil Rights Hearings. Cambridge, MA: Harvard University Press, 1997.

MIGUEL, Luis Felipe. "Política de interesses, política de desvelo: representação e 'singularidade feminina'". Revista Estudos Feministas, v. 9, n. 1, p. 253-67, 2001.

"Perspectivas sociais e dominação simbólica: a presença política das mulheres entre Iris Marion Young e Pierre Bourdieu". Revista de Sociologia e Política, v. 18, p. 25-49, 2010. 
MIGUEL, Luis Felipe; BIROLI, Flávia. Caleidoscópio convexo: mulheres, política e mídia. São Paulo: Editora da UNESP, 2011.

MOI, Toril. What is a Woman? New York: Oxford University Press, 1999.

OKIN, Susan Moller. Justice, Gender, and the Family. New York: Basic Books, 1989a.

"Reason and Feeling in Thinking about Justice". Ethics, Chicago, v. 99, n. 2, p. 229-249, 1989b.

"Gender, the Public and the Private". In: PHILLIPS, Anne (ed.). Feminism and Politics. Oxford: Oxford University Press, 1998. p. 116-141.

PATEMAN, Carole. The Problem of Political Obligation: A Critique of Liberal Theory. Berkeley, Los Angeles: University of California Press, 1985[1979].

The Disorder of Women. Stanford: Stanford Univesity Press, 1989.

PHILLIPS, Anne. Engendering Democracy. Cambridge: Polity Press, 1991.

Multiculturalism without Culture. Princeton: Princeton University Press, 2007.

RUDDICK, Sarah. Maternal Thinking: Towards a Politics of Peace. Boston: Beacon Press, 1989.

SCOTT, James C. Weapons of the Week: Everyday forms of Peasant Resistance. New Haven and London: Yale University Press, 1985.

Domination and the Arts of Resistance: Hidden Transcripts. New Haven and London: Yale University Press, 1990.

SEITER, Ellen. "The 'Terms' of Women's Stereotypes". Feminist Review, n. 22, p. 58-81, 1986.

SUNSTEIN, Cass R. "Preferências e política". Revista Brasileira de Ciência Política, n. 1, p. 219-254, 2009[1991].

WOLF, Naomi. The Beauty Mith. How Images of Beauty Are Used Against Women. New York: Harper Perennial, 2002[1991].

YOUNG, Iris Marion. Intersecting Voices: Dilemmas of Gender, Political Philosophy, and Policy. Princeton: Princeton University Press, 1997. . Inclusion and Democracy. Oxford: Oxford University Press, 2000.

. On Female Body Experience. Oxford: Oxford University Press, 2005.

[Recebido em outubro de 2011 , reapresentado em abril de 2012 e aceito para publicação em maio de 2012] 


\begin{abstract}
Autonomy, Oppression and Identities: Resignifying Experiences in Feminist Political Theory

Abstract: This article analyses different approaches of the connection between autonomy, oppression and identities in feminist political theory. Starting from the concepts of "lived body" and "lived knowledge", it discusses the possibilities of resignifying experiences and autonomously defining identities in social contexts where inequality prevails. It focuses on the fact that identities, although important to the individuals, may reproduce values which are the basis for subalternity, justifying the present forms of oppression. On the other hand, it considers how individuals would actively answer to the restricting alternatives offered by the power structures, being able to confront and redefine them. In this way, it considers theoretical alternatives in those approaches that permit to surpass the duality between autonomous choices and coercion.
\end{abstract}

Key Words: Gender; Feminist Political Theory; Autonomy; Oppression; Identity; Experience. 